\title{
Tramas, redes e escafandristas: notas sobre a educação e o comum na pesquisa em Psicologia
}

\author{
Flávia Cristina Silveira Lemos \\ Universidade Federal do Pará - Belém - PA - Brasil \\ Daniele Vasco Santos \\ Universidade Federal do Pará - Belém - PA - Brasil \\ Geise do Socorro Lima Gomes \\ Universidade Federal do Pará - Belém - PA - Brasil \\ Dolores Galindo \\ Universidade Federal de Mato Grosso - Cuiabá - MT - Brasil
}

\section{Resumo}

O presente artigo visa refletir teoricamente sobre as dimensões do plano da experiência do comum na pesquisa por meio da composição de tramas que favorecem agenciamentos coletivos de saberes, poderes e subjetividades. A busca por intercessores e formação de redes possibilita inventar e politizar as relações, os corpos, pensar a produção da verdade, encarnada e atravessada por afetos. Os saberes são legados partilhados e resultam dos encontros potentes entre conversas e perguntas, na trama das forças heterogêneas e múltiplas que os constituem. Transversalizar e multiplicar os intercessores pela prática transdisciplinar implica ampliar perspectivas, fazer deslizar os lugares institucionais e subjetivos para desnaturalizar práticas cristalizadas e produzir novas histórias colaborativas entre pesquisadores e docentes, na Psicologia e na educação.

Palavras-chave: Pesquisa; Educação; Psicologia.

\section{Weaves, networks and divers: \\ notes about of education and the common in psychological research}

\begin{abstract}
This article aims to reflect theoretically about the common experience of the plan dimensions in research through the composition of plots favoring collective assemblages of knowledge, power and subjectivity. The search for intercessors and networking enables invent and politicize relations, bodies, thought the production of truth incarnated and crossed by emotions. Knowledge is shared legacy and result of meetings between powerful conversations and questions, in the plot of heterogeneous forces and multiple that constitute them. Mainstreaming and multiply intercessors for transdisciplinary practice involves expanding perspectives, slide the institutional and subjective places to denature the crystallized practices and produce new collaborative stories between researchers and teachers, in psychology and in education.
\end{abstract}

Keywords: Research; Education; Psychology.

\section{Tramas, redes y escafandristas:}

\section{notas sobre la educación y el común en la investigación en psicología}

\section{Resumen}

El presente artículo visa el reflejar teóricamente sobre las dimensiones del plan da experiencia del común, en la investigación, por intermedio de la composición de tramas que favorecen agenciamientos colectivos de saberes, poderes y subjetividades. La búsqueda por intercesores y formación de redes posibilita inventar y politizar las relaciones, los cuerpos, pensar la producción de la verdad, encarnada y atravesada por afectos. Los saberes son legados compartidos y resultan de los encuentros potentes entre conversas y preguntas, en la trama de las fuerzas heterogéneas y múltiples, a las cuales los constituyen. Transversalizar y multiplicar los intercesores por la práctica transdisciplinar implica en ampliar perspectivas, hacer deslizar los lugares institucionales y subjetivos, para; así, desnaturalizar prácticas cristalizadas y producir nuevas historias colaborativas entre investigadores y docentes, en la Psicología y educación.

Palabras clave: Pesquisa; Educación; Psicología. 


\section{Introdução}

A lógica de um pensamento não é um sistema racional em equilíbrio. Mesmo a linguagem parecia a Foucault um sistema longe do equilíbrio, ao inverso dos linguistas. A lógica de um pensamento é como um vento que nos impele, uma série de rajadas e de abalos. Pensava-se estar no porto, e de novo se é lançado ao mar... (Deleuze, 1992, p. 118).

O presente artigo é uma problematização teórica, que pretende apresentar uma análise entre os campos da educação, a pesquisa em Psicologia e o plano do comum, tanto na escrita como na leitura. A colaboração entre pesquisadores no trabalho de investigação em Psicologia nas universidades se tornou crucial no presente. Podemos afirmar que as redes de pesquisa, ao serem formalizadas, forjam dispositivos e os instalam no âmbito da micropolítica, os quais, por sua vez, criam condições para que o colaborativo possa emergir, ao mesmo tempo em que se torna uma premissa para que esse dispositivo do comum possa operar. Um dos objetivos deste texto é problematizar a experiência do comum entre estudiosos e as resistências construídas no bojo da tentativa de captura dessa prática pelas malhas do capital e do excesso de produção que aniquila a solidariedade e o pensar como atitude crítica.

De uma parte, pode-se pensar a prática do trabalho coletivo entre pesquisadores como resposta às encomendas por produtividade, que podem culminar em efeitos perversos, ao tentar estancar o pensamento em prol de indicadores apenas mensuráveis. É possível pensar também que, no exterior ou no interstício da prática científica nacional, as colaborações extrapolam finalidades estratégicas mensuráveis de produtividade - ainda que comportem informações quantificáveis e sejam produção, fruto das práticas de trabalho -, compondo um excedente que se dá como potência não coincidente, necessariamente, com as encomendas de produtividade solicitadas pelas agências de fomento à pesquisa.

As redes de pesquisa, definidas pela atuação conjunta, consolidada entre grupos de pesquisa e pesquisadores, na perspectiva de produção da história intelectual, vêm expandindo sua importância política, social e cultural, nos últimos anos, na medida em que uma sociedade do conhecimento emerge contemporaneamente de forma contundente e com intensa valorização (Castells, 2010). Há críticas aos pressupostos da sociedade de conhecimento, no que tange ao aspecto do excesso de informação, da intensa dispersão diante do consumo e produção acelerada das publicações bem como da grande difusão destas. A capitalização do conhecimento na atualidade é uma problemática muito complexa tanto quanto a exigência da formação de redes entre os pesquisadores. Analisar essa dimensão é um dos objetivos deste artigo.

As redes, contudo, em várias pesquisas são a interface pública do campo de colaborações que as desdobram, de maneira que nos cabe, em certa medida, desfetichizar as redes como imagem mais adequada para o que fazemos em nosso cotidiano de pesquisa, em termos de obrigação de fazer a rede acontecer enquanto capital relacional, em uma lógica empresarial e de investimento da sociabilidade.

Dessa forma, este artigo, em formato de ensaio, pretende abordar alguns planos da produção da pesquisa científica em Psicologia e trazer ferramentas conceituais que possam contribuir para o acompanhamento com a análise dos planos da experiência do comum na investigação tanto pela transversalidade quanto pela transdisciplinaridade, em que a escrita, a leitura, a educação e a estética docente podem potencializar resistências ao capital social e do conhecimento, construindo um trabalho colaborativo pela instauração do comum da amizade filosófica.

\section{Transversalidade e transdisciplinaridade na pesquisa}

O conceito de transversalidade, proposto por Félix Guattari na década de 1960 tem funcionado como um conceito dispositivo importante para refletir sobre diferentes configurações que têm se formado acerca do pensamento, sobretudo, na "modernidade". Uma dessas configurações pode ser notada na lógica "arborescente" que predomina em muitos campos de conhecimento, fazendo funcionar binarismos desmontados por Guattari (2004) e Deleuze e Guattari (2011). "A árvore e a raiz inspiram uma triste imagem do pensamento que não para de imitar o múltiplo a partir de uma unidade superior, de centro ou de segmento" (Deleuze \& Guattari, 2011, p. 35).

Nessa lógica "arborescente", tenta-se sustentar uma unidade pivô principal, a fim de sustentar uma política da produção da verdade e a hierarquização de saberes por poderes, em uma dinâmica relacional. Ao funcionar por meio de "sistemas fechados" essa lógica impede a visibilidade e o funcionamento de dimensões que agem por meio de multiplicidades, mudando à medida que elas aumentam suas conexões. Em Mil Platôs (Deleuze \& Guattari, 2011, p. 43), a metáfora do "rizoma" é explicitada por esses autores, a fim de colocar em questão esse modelo "arborescente":

... Oposto a uma estrutura, que se define por um conjunto de pontos e posições, por correlações binárias entre estes pontos e relações biunívocas entre estas posições, o rizoma é feito somente de linhas: linhas de segmentariedade, de estratificação, como dimensões, mas também linha de fuga ou de desterritorialização como dimensão máxima segundo a qual, em seguindo-a, a multiplicidade se metamorfoseia, mudando de natureza.

A transversalidade, entendida como um conceito/ dimensão tem um funcionamento rizomático, porque reconhece a pulverização, a multiplicidade, estando atenta às diferenças e à diferenciação (Gallo, 2003; Matias, 2008). Para tanto, rompe com a lógica da verticalidade, em que pontos e saberes distintos são hierarquizados, e com a lógica da 
horizontalidade, que faz pensar conexões apenas entre semelhanças ou afinidades (Guattari, 2004). Da mesma forma que o rizoma, apresenta mobilidade em todos os sentidos (Matias, 2008).

Pensar na transversalidade, portanto, é imaginar movimento, trânsito, entre diferentes disciplinas e saberes e comunicação nos diferentes níveis e sentidos. Assim, transversalidade e rizoma tornam-se dois conceitos importantes, com forte comunicação entre si, exigindo passagem, deslocando conceitos, identidades, desinstitucionalizando e rompendo hierarquias, criando linhas de fugas, na produção das multiplicidades e das diferenças. Tomando-se como referência a filosofia da diferença de Gilles Deleuze, postula-se o conceito de diferença como o resultado provisório de um processo de singularização, sendo que um de seus aspectos cruciais é a multiplicidade e a descontinuidade. Nessa lógica, o pensamento é desbloqueado de todo movimento ligado às perspectivas identitárias, o que permite a emergência da singularidade como efeito dos processos de subjetivação complexos, imanentes e sem relações de causalidade mecanicistas e reducionistas.

A multiplicidade implica em muitas práticas em relações indeterminadas de composição, sem prevalência de qualquer uma delas sobre as demais. A descontinuidade é o plano da história da formação da subjetividade pelos processos de subjetivação por rupturas e atualizações e não por totalidade e essência. A descontinuidade é uma crítica da essência de um suposto sujeito e da verdade que the constituiria. Desse modo, as práticas são fazeres que forjam verdades, subjetividades, relações, geram efeitos de poder, de saber e criam realidades, sem remissão à consciência como soberania de um sujeito e sem partir das visões causais e binárias.

Escrever, fazer rizoma, aumentar o seu território por desterritorialização, estender a linha de fuga até o ponto em que ela cubra todo o plano de consistência em uma máquina abstrata... Uma das características mais importantes do rizoma talvez seja a de ter sempre múltiplas entradas. (Deleuze \& Guattari, 2011, pp.28-30).

A transversalidade, pois, segundo Yonezawa (2013), vai produzir "espaços de trânsitos das diferenças". "Um grande coeficiente de transversalidade implica um olhar inquieto sobre o mundo e numa sensibilidade capaz de se afetar por quantidade de diferença da realidade" (Yonezawa, 2003, p. 4). Ou seja, a transversalidade é constituída por linhas de devir, que abrem espaços para a criação.

Próximo ao conceito de transversalidade, Benevides (s.d.) traz o conceito de transdisciplinaridade, aludindo ao cotidiano das instituições, onde os saberes se hierarquizam. Mesmo nas proposições de "multidisciplinariedade" e "interdisciplinaridade", o saber continua demarcado em campos próprios, específicos, criando objetos e subjetividades. Para a autora, é preciso propiciar um encontro entre os saberes, mas aproveitando o espaço onde eles se cruzam, fazendo destes uma produção do pensamento, de novos conceitos; forçando os saberes a irem além das fronteiras, dos seus lugares conhecidos, atravessando as disciplinas, ou seja, realizar um trabalho entre, e não dentro.

Assim, poderíamos afirmar que a transdisciplinaridade seria um movimento de ruptura das disciplinas, não tendendo nem para o campo de consolidação da subjetividade, nem para o do objeto, como, por exemplo, considerando que ambos são produtos de criação e intervenção. "A noção de transdisciplinaridade subverte o eixo de sustentação dos campos epistemológicos, graças ao efeito de desestabilização tanto da dicotomia sujeito/objeto quanto da unidade das disciplinas e dos especialismos" (Passos \& Barros, 2000, p. 76).

Podemos dizer que essa criação das disciplinas e dos especialismos está subjugada a um controle dos discursos e seu sistema de produção, de distribuição e de circulação acadêmica que operam uma política da verdade. A escrita e a leitura passam por crivos de sistemas de repartição discursiva, campos de valorização dos saberes, em uma determinada sociedade, práticas de poder editoriais, apropriações educativas e procedimentos de avaliação e classificação, em ordens do discurso específicas (Foucault, 2004a).

Há ainda uma prática que tenta articular o autor à sua obra, forjando uma intencionalidade entre escrita, leitura e história de vida. Em geral, tem servido para fazer um jogo de vigilância entre moral e valor da publicação, no sentido de que a qualidade de uma suposta obra estaria vinculada ao escrutínio dos acontecimentos da pessoa do autor (Foucault, 2006).

As visões de obra, influências e autoria são analisadas por Michel Foucault (2009), colocadas em xeque para poder interrogar intencionalidades de um sujeito da consciência, continuidades históricas, noções de tempo cronológico, perspectivas de criação de uma personalidade do autor, na obra veiculada, e, por fim, a própria ideia de obra é questionada, por implicar uma classificação de totalidade das publicações realizadas, conferindo a estas um suposto sentido linear.

Foucault seria um exemplo de pesquisador que passou por esse crivo de ter sua vida devastada por biógrafos, com o objetivo de desvalorizar a sua produção escrita, se assim pudéssemos caracterizar Foucault, pois ele sempre rejeitou enquadramentos disciplinares que o impedissem de fazer circular os saberes pelas fronteiras discursivas e subjetivas dos controles da verdade, no contemporâneo (Albuquerque Jr., 2007).

Os vestígios eram rastros, na areia do deserto, porque já não estavam mais nos lugares em que gostariam de encontrar Foucault. Ele se movia e sem continuidade; dessa maneira, deixou um legado de transversalidade, transdisciplinaridade e conversações com vários intercessores, além de um campo de saberes das ciências. Seus intercessores também eram músicos, pintores, saberes nomeados como desqualificados, literatura, cinema, descontinuidades de movimentos sociais, discursos pelos quais quase ninguém mais se interessava, nas bibliotecas de diversos países. Por tal razão, suspeitamos que, talvez, seja mais uma artimanha 
não deixar pistas para escafandristas nem sábios que visam identificar o que fazemos de nós mesmos, nossos desvãos:

Os escafandristas virão/ Explorar sua casa/ Seu quarto, suas vidas/ Sua alma, desvãos/ Sábios em vão/ Tentarão decifrar/ O eco de antigas palavras/ Fragmentos de cartas, poemas/ Mentiras, retratos/ Vestígios de estranha civilização (Chico Buarque, 1993).

Nesse sentido, ressaltamos a importância que há em perceber, por exemplo, de que maneira alguns buscavam fazer a biografia de Foucault para colá-la à função de autor, de historiador e, outros, de filósofo ou psicólogo, procurando onde ele estava, em que área, conversando com quem, rastreando para qual lugar ele estaria viajando ou encaminhando as pesquisas para que área e tema. Uma política biográfica e avaliativa dos percursos sobre as quebras de fronteiras disciplinares, das áreas, dos temas, da escrita e dos intercessores era marcadamente vigiada, no passo a passo de Michel Foucault. Parecia que essas quebras de fronteiras representavam algum tipo de perigo a mapear e a dissuadir (Veyne, 2008).

\section{A escrita e leitura como plano de experiência e subjetividade: uma micropolítica}

A escrita pode ser um intercessor de uma conversação entre pesquisadores e, igualmente, na relação entre orientador e orientandos, entre pesquisadores afastados geograficamente. Por meio da escritura podemos produzir um encontro potente de atravessamentos e compartilhamentos de saberes. A escrita auxilia a superar dificuldades como perdas e ruínas (Foucault, 2004a). Todavia, outro tipo de conversação se estabelece pelas anotações e pelos atravessamentos que as mesmas forjam, ao circularem, em leituras e problematizações realizadas.

A relação instaurada na escrita pode ser de interferência e intervenção, por meio do atravessamento desestabilizador de qualquer domínio, como ressaltam Passos e Barros (2000): disciplinar, conceitual, artístico, sociopolítico e outros. Assim, observamos que, pelo exercício de escrever, nessa proposta de estremecer a escrita instituída, são constituídos campos de diálogos que dizem respeito às experimentações daqueles que fazem das palavras organização do pensamento, invenção de passagens outras para o que não tem lugar determinado na ordem do dia. Diante das possibilidades de criação, surgem novos arranjos teóricos e conceituais, os quais amparam diferentes entendimentos sobre o mundo. Possibilidades, então, de uma escrita que incita a produção da diferença.

Em seu movimento de intercessão os conceitos são imediatamente ferramentas, porque se constroem num certo regime de forças. Não são abstratos, não são dados, não são preexistentes. Eles compõem, o tempo todo, um sistema aberto relacionado a circunstâncias, e não mais a essências.
É por isso que dizemos que precisamos inventar conceitos, criar conceitos que tenham necessidade. (Passos \& Barros, 2000, p. 77).

De acordo com Deleuze (1992), uma conversa pode funcionar também como intercessora, compondo um diagrama de práticas que coexistem e criam ressonâncias as quais não se limitam ao encontro realizado, pois transbordam nos corpos e nos entremeios, afetando outros grupos, colegas de trabalho e espaços. Assim, as práticas dos grupos se enredam e se atravessam, em agenciamentos coletivos de escrita na pesquisa científica.

Desse modo, a escrita, ao invés de ser pensada como último momento do trabalho de pesquisa, há de se abrir para que esta possa ser situada para além do registro. Como lembram Passos e Barros (2000), cada conceito está relacionado a um conjunto de forças, constituindo um plano em que fluxos diversos se transpõem. Para os autores, um conceito funciona como um "intercessor", tal como Deleuze opera com essa noção. Nesse sentido, é preciso percorrer as linhas que constituem esse conceito, dar visibilidade às relações estabelecidas a partir dos movimentos de estranhamento de si e dos próprios fazeres, a fim de se abrir ao deslocamento da escrita e da conversação coletiva, em um gaguejar na própria língua, conforme Certeau (2011), pois a escrita é a materialidade da diferença.

O mais importante para ativar intercessores é o movimento que estes deslocam, produzindo interferência entre domínios, instaurando a diferença: ao transdisciplinarizar, problematizamos os limites de cada disciplina, ou seja, trata-se de uma forma de "argila em seus pontos de congelamento e universalidade..., de nomadizar as fronteiras, torná-las instáveis" (Passos \& Barros, 2000, p.77).

A leitura permite buscar a construção de táticas e elementos para pensar, não pelo acúmulo de informação e formação de um sujeito da opinião informado (Foucault, 2004b). Ler é nomadizar e experimentar mundos outros, uma experiência de estranhamento de si e do que está dado. Os livros, artigos, textos, poesias, literaturas variadas, imagens e discursos diversos podem também ser lidos e apropriados por práticas de conversação e forjar modos de ser, subjetividades, em uma micropolítica (Deleuze, 2004).

O cotidiano da leitura alimenta modos de viver e pensar, de agir e se relacionar, compõe uma materialidade educativa a qual pode fazer transbordar vivências anteriores e atravessá-las com outras linhas, deslocando o pensamento e fazendo ranger o já cristalizado (Chartier, 2002). Por isso, Foucault (2004b) destaca que o ato de ler sem escrever provoca dispersão do pensamento, enquanto escrever continuamente sem ler traz exaustão e esgotamento.

O tempo da leitura e da escrita não é o mesmo da produtividade cronológica, implicando uma descontinuidade entre as experiências de ler e escrever, articuladas à fabricação da subjetividade e à apropriação discursiva pela invenção possível de saberes, em relações de forças, na dinâmica de poder enquanto positividade de incitar e produzir 
algo, fazer passar um plano de forças móveis e agenciadas em um texto (Foucault, 2004b).

Contudo, nos emaranhados das intensas construções que se dão junto aos intercessores, disputas são estabelecidas, conduzindo a específicos usos e endereçamentos das produções literárias e escritas, em um campo de circulação dos saberes e publicações distribuídas.

Por isso, cabe questionar: acionar uma escrita que se ligue a políticas de pesquisa não adstritas estreitamente a finalidades é o que fazem muitos pesquisadores de Psicologia, em suas práticas? Mesmo que as publicações sejam aquilo que emerge do plano comum e colaborativo, não é em prol do incremento de índices que escrevemos. O mesmo pode ser evidenciado no esforço da área de Psicologia, na internacionalização, indexação e qualificação dos periódicos da área. Atuar nas políticas editoriais é parte do plano comum do fazer ciência. Políticas de escrita e de publicação podem comportar, de acordo com o argumento que seguimos neste ensaio, atos estéticos de invenção.

Nesse sentido, essa prática aponta um ethos, uma atitude crítica face ao presente vivido e acarreta uma postura estética e política, um posicionar-se, na atualidade, por meio de perguntas e inquietações, e que não pretende, por sua vez, identificar-se a uma corrente e a uma área que figurasse como uma impossibilidade de romper fronteiras e de ampliar os intercessores.

\section{Estética educativa e experiência dos corpos}

A experiência estética da invenção é uma modalidade de arquivo de acontecimentos, das intensidades das experiências e dos seus lampejos. Segundo Sforzini (2014), é útil poder experimentar, no corpo e através do corpo, o pensar interrogante e a produção de si concomitantemente ao cuidado com o outro.

Nessa experiência, de natureza estética, um processo de desterritorialização de existências se realiza por meio dos atravessamentos de saberes em um corpo, marcado pela história, o qual não pode ser negado na pesquisa, pois o pensamento inunda e se prolifera, encarnado e na intensidade das forças agenciadas nas vivências de estudo e escrita universitária, tanto quanto em outras experiências estéticas.

Uma educação outra pode ser experimentada pela invenção e pela singularização das práticas de pesquisa, de orientação e ensino, propiciando o que Larrosa (2004) designou como experiência e não apenas cumprimento de obrigações acadêmicas. Um movimento de dança, de poesia e música foi ganhando possibilidade de transformar a didática em arte, tal qual Corazza (2012) relata, em seus estudos sobre diferença na educação. Uma prática libertária era tecida cotidianamente, inquietante e aberta aos processos de invenção próxima ao que Gallo (2012) descreveu como experiência criativa na educação.

Corazza (2004) nomeou essa prática como estética docente através de um processo criativo, em um fabricar-se enquanto artesão da potência de diferir no ensino. A pesquisa e a orientação desta, em grupo e pelas redes entre pesquisadores, extrapola o trabalho prescrito e ganha dimensão de problemática, a partir de uma dramática da existência, na esfera do que Schwartz (2000) denominou trabalho vivo.

A estética com a política opera igualmente artesanatos interessantes, na dimensão das participações de pesquisadores na politização de seus corpos e dos seus alunos, como as vivenciadas em passeatas, movimentos sociais, representações em conselhos profissionais e de direitos. A produção política de intelectuais e suas incidências, em associações, em cargos públicos, em decisões do Estado, em seus escritos nas mídias, na reverberação de suas publicações e palestras fora da universidade, vêm sendo estudadas na história política, intelectual, cultural e na sociologia do conhecimento (Carvalho, 2000; Pécault, 1989; Sirinelli, 2003).

Observa-se que, nessa partilha, há explicitação dos enunciados coletivamente, conforme salientaram Deleuze e Guattari (1996), por se tratar de agenciamentos no coletivo, pelo coletivo e além dele. A circulação, o acesso e a apropriação de saberes ganha uma nova dimensão, com base na criação e difusão da internet (Castells, 2010; Levy, 2010). Nesse sentido, "o enunciado é o produto de um agenciamento, sempre coletivo..." (Deleuze, 2004, p. 69).

O campo do comum possibilita dizer algo aos amigos de pesquisa, permite fazer ecoar acontecimentos insólitos, em que a escrita forja um corpo de exercício do pensamento, a partir do que se leu e das experimentações realizadas. Um dos efeitos é fazer circular a fala e os saberes em ressonâncias múltiplas além das conversas presenciais. "É isso, agenciar: estar no meio, na linha de encontro..." (Deleuze, 2004 , p. 70). Essa reciprocidade faz recuar individualismos e favorece novas maneiras de ensinar, estudar, pesquisar e orientar. Tal movimento vai constituindo o que Deleuze (1992) chamou de diálogo com os intercessores: colegas, livros, cheiros, músicas, poesias, filmes, documentários, artes visuais.

Uma atitude problematizadora face ao presente e às práticas de pesquisa ocorre simultaneamente ao deslocamento subjetivo dos agenciamentos coletivos (Gros, 2014). Assim, Deleuze (1992, p. 156) afirmava: "eu preciso de meus intercessores para me exprimir, e eles jamais se exprimiriam sem mim: sempre se trabalha em vários, mesmo quando isso não se vê".

No interior das universidades, a circulação discursiva facilita a ruptura da separação entre graduação e pós-graduação. Os muros das salas de aulas e blocos, divididos por institutos, por disciplinas e áreas podem ser perfurados, e brechas são inventadas. Amizades vão sendo constituídas, a partir da circulação de saberes (Ortega, 1999). Como apontava Lapassade (1989), a palavra dos grupos sociais precisa circular para romper com a burocracia e a hierarquia dos discursos.

A criação são os intercessores. Sem eles não há obra. Podem ser pessoas - para um filósofo, artistas ou, cientistas; para um cientista, filósofos ou artistas - mas também coisas, 
plantas, até animais, como em Castañeda. Fictícios ou reais, animados ou inanimados, é preciso fabricar seus próprios intercessores (Deleuze, 1992, p. 156).

Tratamos de uma micropolítica tal qual proposta por Guattari e Ronilk (1996), uma aposta na singularização pelos encontros e nas dissidências criativas, por meio da produção de conversações e escritas colaborativas. Ora, não haveria como contribuir para coletivizações dos saberes, conexões de corpos, ética na pesquisa e em uma politização inventiva da verdade, fora de uma prática de construção do comum.

\section{Considerações, escafandristas e sábios a nos decifrar?}

Em meio às maresias e multiplicidade de sensações que atravessam aqueles que se deixam à deriva, observamos, conforme Mehry (2007), que o trabalho vivo é uma resistência ao sofrimento da dureza e repetição do prescrito. A produção da saúde na universidade e pela pesquisa é como tomar ar e apostar no possível de uma educação não limitada às regras da competição e do utilitarismo na produção.

O trabalho vivo é uma prática de resistir à dramática do trabalho morto, ou seja, a ação de transformar prescrições de repetição e burocracia cristalizada de exercícios automáticos da escrita e da leitura, por exemplo, em potência problemática, interrogante da reprodução em nome da abertura da criação no trabalho pelas perguntas, as quais permitam desnaturalizar uma produtividade mecânica, no trabalho de pesquisa. A experiência de criar grupos de pesquisa, impulsionada por políticas científicas dirigidas às universidades e de tecer a interlocução com colegas pesquisadores é, também, um modo de forjar travessias e percursos de resistências ao prescrito pelo currículo e pelas avaliações comparativas da produção acadêmica (Schwartz, 2000).

A publicação científica é condição axial do plano comum de experiência ao qual aludimos, e assumiria a difícil condição de possibilidade para pesquisadores e pesquisadoras situados geograficamente distantes dos grandes centros de produção acadêmica. Os periódicos científicos, principalmente depois da disponibilização do conteúdo em acesso aberto ou nos portais e repositórios mantidos pelo Ministério da Educação, são intercessores importantes, ao lado dos livros e outras veiculações.

Os modos de produzir, divulgar, publicar, fazer circular e distribuir saberes se referem à cultura específica, a uma determinada sociedade, às suas formas de subjetivação e às suas maneiras de organizar o trabalho, de forma datada historicamente. Por tal razão, torna-se interessante observar que, na história dos intelectuais, há uma preocupação em fazer o mapa das conversas, das cartas trocadas, dos diários de campo dos pesquisadores, dos postais enviados, dos e-mails endereçados, do currículo e das publicações realizadas (Harlan, 2000).

Pelas descrições de Le Goff, em Os Intelectuais na Idade Média (2003), vemos que existem testemunhos, frag- mentos de vida, anotações de livros lidos, coisas ouvidas e pensadas. Há arquivos a compor nos traços pouco visíveis do que se convencionou chamar redes de pesquisa, no Brasil, que as extrapolam e remetem a alguns dos intercessores que abordamos.

As caixas de correio eletrônico e os arquivos dos grupos virtuais dos quais participam pesquisadores em trabalhos colaborativos, ao lado da produção científica propriamente dita, formam rastros para escafandristas e matéria viva da nossa ontologia. "... O filósofo, o cientista, o artista [ainda] parecem retornar do país dos mortos..." (Deleuze \& Guattari, 2013, p. 238), no presente?

Uma genealogia dos restos, práticas que se depositam nas camadas abissais dos oceanos que as redes não logram cartografar: e aí está uma brecha para criar da dramática uma problemática do pensar, escrever, ler e elaborar um comum não cooptado pelo empresariamento da educação. Criticar a atitude automática e mecânica de uma sujeição à capitalização do conhecimento e instrumentalização da prática colaborativa, esvaziando-a da amizade filosófica, é um ato de resistência, na atualidade, nada fácil em constituir.

Não é por acaso que os corpos de pesquisadores que se lançam e relançam ao mar em movimento incessante - os quais se aproximam daqueles de viajantes que se recriam no trânsito do desconhecido - são transformados em hospedagem temporária para as narrativas condizentes com os mares os quais atravessam. Nos processos de investigação, todo elemento pertinente ao lugar de existência de quem investiga entra em cena, compondo continuidades e descontinuidades sobre o modo de se fazer pesquisa, ou seja, de se pôr em estado de deriva.

Assim, os lugares da história dos pesquisadores vão potencializando deslocamentos dos que escrevem e se apropriam dos acontecimentos analisados (Farge, 2011). Nesse aspecto, considerar os arquivos da escrita e da leitura que podemos chamar informais de pesquisa pode "ativar saberes locais, descontínuos, desqualificados, não legitimados, contra a instância teórica unitária que pretenderia depurá-los, hierarquizá-los, ordená-los em nome de um conhecimento verdadeiro" (Foucault, 1979, p. 171).

Finalizando, o leitor e o escrito deveriam se transfigurar face aos novos regimes de escrita e de leitura, no contemporâneo, na medida em que as práticas de gestão dos discursos e seus suportes estão sendo transformadas, e os procedimentos de avaliação passam a ser cada vez mais rigorosos e detalhistas, no plano acadêmico. Resistir pela escrita colaborativa e amizade filosófica é uma tática e estratégia dissidente e potencializadora de novos deslocamentos de um artesanato da experimentação escrita e literária, no presente.

\section{Referências}

Albuquerque Júnior, D. M. (2007). História: a arte de inventar o passado - Ensaios de teoria da história. Bauru: EDUSC. 
Benevides, R. (s.d.). Complexidade, transdisciplinaridade e produção de subjetividade. Recuperado: 28 mai. 2015. Disponível: http:// www.slab.uff.br/antigo2/images/Aqruivos/textos_sti/Regina\%20 Benevides/texto33.pdf.

Carvalho, J. M. (2000). História intelectual no Brasil: a retórica como chave de leitura. Topoi, 1, 145.

Chartier, R. (2002). Os desafios da escrita. São Paulo: Editora UNESP.

Buarque, C. (1993). Futuros Amantes. Em Paratodos. Marola Edições Musicais Ltda.

Castells, M. (2010). A sociedade em rede (Vol. I). Rio de Janeiro: Paz e Terra.

Certeau, M. (2011). A escrita da História. Rio de Janeiro: Forense.

Coimbra, C. M. B. \& Nascimento, M. L. (2012). Sobreimplicar. Em T. M. G. Fonseca, M. L. Nascimento \& C. Maraschin. (Orgs.), Pesquisar na diferença: um abecedário (pp. 211-213). Porto Alegre: Sulina.

Corazza, S. M. (2004). Artistagens: filosofia da diferença e educação. Belo Horizonte: Autêntica.

Corazza, S. M. (2012). Didaticário de criação: aula cheia. Porto Alegre: UFRGS.

Deleuze, G. (1992). Conversações. Rio de Janeiro: Editora 34.

Deleuze, G. (2004). Diálogos. Porto: Relógio D’Água.

Deleuze, G. \& Guattari, F. (1996). Mil platôs I: capitalismo e esquizofrenia. Rio de Janeiro: Editora 34.

Deleuze, G. \& Guattari, F. (2011). Mil Platôs II: capitalismo e esquizofrenia. São Paulo: Editora 34.

Deleuze, G. \& Guattari, F. (2013). O que é a filosofia? Rio de Janeiro: Editora 34.

Farge, A. (2011). Lugares para a história. Rio de Janeiro: Autêntica.

Foucault, M. (1979). Microfísica do poder. Rio de Janeiro: Graal.

Foucault, M. (2004a). A ordem do discurso. São Paulo: Loyola.

Foucault, M. (2004b). A escrita de si. Em M. B. da Motta (Org.), Michel Foucault: ética, estética e política (pp. 144-162). Rio de Janeiro: Forense Universitária.

Foucault, M. (2006). O que é um autor? Em: Ditos e Escritos III Estética: literatura e pintura; música e cinema. Rio de Janeiro: Forense Universitária.
Foucault, M. (2009). Arqueologia do saber. Rio de Janeiro: Forense.

Foucault, M. (2010). A hermenêutica do sujeito. São Paulo: Martins Fontes.

Gallo, S. (2003). Deleuze e a Educação. Belo Horizonte. Autêntica.

Gallo, S. (2012). Anarquismo e educação: os desafios de uma pedagogia libertária. Política \& Trabalho. Revista de Ciências Sociais, 36, 169-186.

Guattari, F. (2004). A transversalidade. Em F. Guattari, Psicanálise e transversalidade: ensaios de análise institucional. Aparecida /SP: Ideias \& Letras.

Guattari, F. \& Rolnik, S. (1996). Micropolítica: cartografias do desejo. Petrópolis/RJ: Vozes.

Gros, F. (2014). Problématisation. Em J.-F. Bert \& J. Lamy (Orgs.), Michel Foucault. Un heritage critique (pp. 125-126). Paris: CNRS.

Harlan, D. (2000). A história intelectual e o retorno da Literatura. Em M. Rago \& R. A. O. Gimenes (Orgs.), Narrar o passado, repensar a história (p.21). Campinas: UNICAMP - Instituto de Filosofia e Ciências Humanas.

Lapassade, G. (1989). Grupos, organizações e instituições. Rio de Janeiro: Francisco Alves.

Larrosa, J. (2004). Linguagem e educação depois de Babel. Belo Horizonte: Autêntica.

Le Goff, J. (2003). Os intelectuais na Idade Média. Rio de Janeiro: José Olympio.

Levy, Pierre. (2010). Cibercultura. Rio de Janeiro: Editora 34.

Matias, V. C. B. Q. (2008). A transversalidade e a construção de novas subjetividades pelo currículo escolar. Currículo sem Fronteiras, 8 (1), 62-75.

Merhy, E. E. (2007). Gestão da produção do cuidado e clínica do corpo sem órgãos: novos componentes dos processos de produção do cuidado em saúde. Recuperado: 10 mar. 2015. Disponível em: $<$ http://www.uff.br/saudecoletiva/professores/merhy/artigos-25. pdf>.

Ortega, F. (1999). Amizade e Estética da Existência em Foucault. Rio de Janeiro: Graal.

Passos, E. \& Barros, R. B. (2000). A Construção do Plano da Clínica e o Conceito de Transdisciplinaridade. Psicologia: Teoria e Pesquisa, 16 (1), 071-079.

Pécault, D. (1989). Os intelectuais e a Política no Brasil. São Paulo: Ática. 
Schwartz, Y. (2000). A comunidade científica ampliada e o regime de produção de saberes. Trabalho \& Educação, 7, 38-46.

Sforzini, A. (2014). Michel Foucault. Une pensée du corps. Paris: Presses Universitaires de France.

Sirinelli, Jean-François. (2003). Os Intelectuais. Em R. Remond (Org.), Por uma história política. Rio de Janeiro: Editora FGV.
Veyne, P. (2008). Foucault. O pensamento. A pessoa. Lisboa: Texto \& Grafia.

Yonezawa, F. H. (2013, jun.). A problematização deleuziana do aprender e do pensar como transversalidade para um currículo educacional. Revista Artifícios, 3 (5).

Recebido em: 01/06/2015

Reformulado em: 16/07/2016

Aprovado em: 18/07/2016

\section{Sobre as autoras}

Flávia Cristina Silveira Lemos (flaviacslemos@gmail.com)

Psicóloga/UNESP, Mestre em Psicologia Social/UNESP, Doutora em História Cultura/UNESP. Professora adjunta IV/UFPA. Bolsista de produtividade em pesquisa CNPQ-PQ2.

Daniele Vasco Santos (danielevasco@yahoo.com.br)

Psicóloga/UFPA. Mestre em Educação/UFPA. Doutoranda em Educação/UFPA.

Geise do Socorro Lima Gomes (geise.gomes@hotmail.com)

Psicóloga/UFPA. Mestre em Psicologia/UFPA. Doutorada em Psicologia/UFPA.

Dolores Galindo (dolorescristinagalindo@gmail.com)

Psicóloga/UFPE. Mestre e Doutora em Psicologia Social/PUC-SP. Professora adjunta de psicologia social/UFMT. 